\title{
Toxic Emissions from Mobile Sources: A Total Fuel-Cycle Analysis for Conventional and Alternative Fuel Vehicles
}

\author{
James J. Winebrake* \\ Michael Q. Wang \\ Dongquan He \\ Argonne National Lab \\ Center for Transportation Research \\ Argonne National Laboratory \\ Argonne, IL 60439 \\ ${ }^{*}$ Also affiliated with the Integrated Science and Technology Program, James Madison \\ University, Harrisonburg, VA, 22807.
}

\begin{abstract}
Mobile sources are among the largest contributors of four hazardous air pollutants (benzene, 1,3butadiene, acetaldehyde, and formaldehyde) in urban areas. At the same time, federal and state governments are promoting the use of alternative fuel vehicles as a means to curb local air pollution. As of yet, the impact of this movement towards alternative fuels with respect to toxic emissions has not been well studied. The purpose of this paper is to compare toxic emissions from vehicles operating on a variety of fuels, including reformulated gasoline, natural gas, ethanol, methanol, liquid petroleum gas, and electricity. This study uses a version of Argonne National Lab's GREET model, appropriately modified to estimate toxic emissions. The GREET model conducts a total fuel-cycle analysis that calculates emissions from both downstream (e.g., operation of the vehicle) and upstream (e.g., fuel production and distribution) stages of the fuelcycle. Our results suggest that the gaseous fuels and electric vehicles show significant decreases in toxic emissions when compared to conventional gasoline vehicles. On the contrary, alcohol blended fuels show increases in aldehydes and butadiene, while exhibiting reductions in benzene compared to gasoline.
\end{abstract}

\section{INTRODUCTION}

Recent analyses indicate that in many parts of the country mobile sources are responsible for the majority of emissions of certain air toxics. ${ }^{1,2}$ These airborne pollutants are either carcinogenic or pose some other significant human health threat. Mobile source toxic emissions are attributed to vehicles operating on petroleum-based fuels that release a variety of complex chemicals when burned or evaporated. Four of the more ubiquitous mobile air toxics are: acetaldehyde, benzene, 1,3-butadiene, and formaldehyde.

Expected future contributions of mobile source air toxics will be a function of the types of fuels and vehicles in use. In many parts of the country, there is an emerging use of alternative fuel vehicles (AFVs) that operate on non-petroleum based fuels. The purpose of this paper is to examine total fuel-cycle toxic emissions from conventional gasoline vehicles (CVs) and AFVs. Total fuel-cycle emissions include emissions from both vehicle operation and also feedstock processing and fuel production and distribution. For our analysis, we employ the Greenhouse 


\section{DISCLAIMER}

This report was prepared as an account of work sponsored by an agency of the United States Government. Neither the United States Government nor any agency thereof, nor any of their employees, make any warranty, express or implied, or assumes any legal liability or responsibility for the accuracy, completeness, or usefulness of any information, apparatus, product, or process disclosed, or represents that its use would not infringe privately owned rights. Reference herein to any specific commercial product, process, or service by trade name, trademark, manufacturer, or otherwise does not necessarily constitute or imply its endorsement, recommendation, or favoring by the United States Government or any agency thereof. The views and opinions of authors expressed herein do not necessarily state or reflect those of the United States Government or any agency thereof. 


\section{DISCLAIMER}

Portions of this document may be illegible in electronic image products. Images are produced from the best available original document. 
Gas, Regulated Emissions, and Energy Use in Transportation model (GREET) developed at Argonne National Laboratory. ${ }^{3,4}$ Although GREET does not currently include toxic components in its analysis, we have modified GREET to evaluate acetaldehyde, benzene, 1,3-butadiene, and formaldehyde emissions.

This paper focuses on emissions from near-term light-duty vehicles (LDV) operating on the fuels shown in Table 1. Table 1 also identifies the upstream and downstream stages considered in the total fuel cycle. More details about these stages are discussed later in the paper.

Table 1. Fuels and stages analyzed.

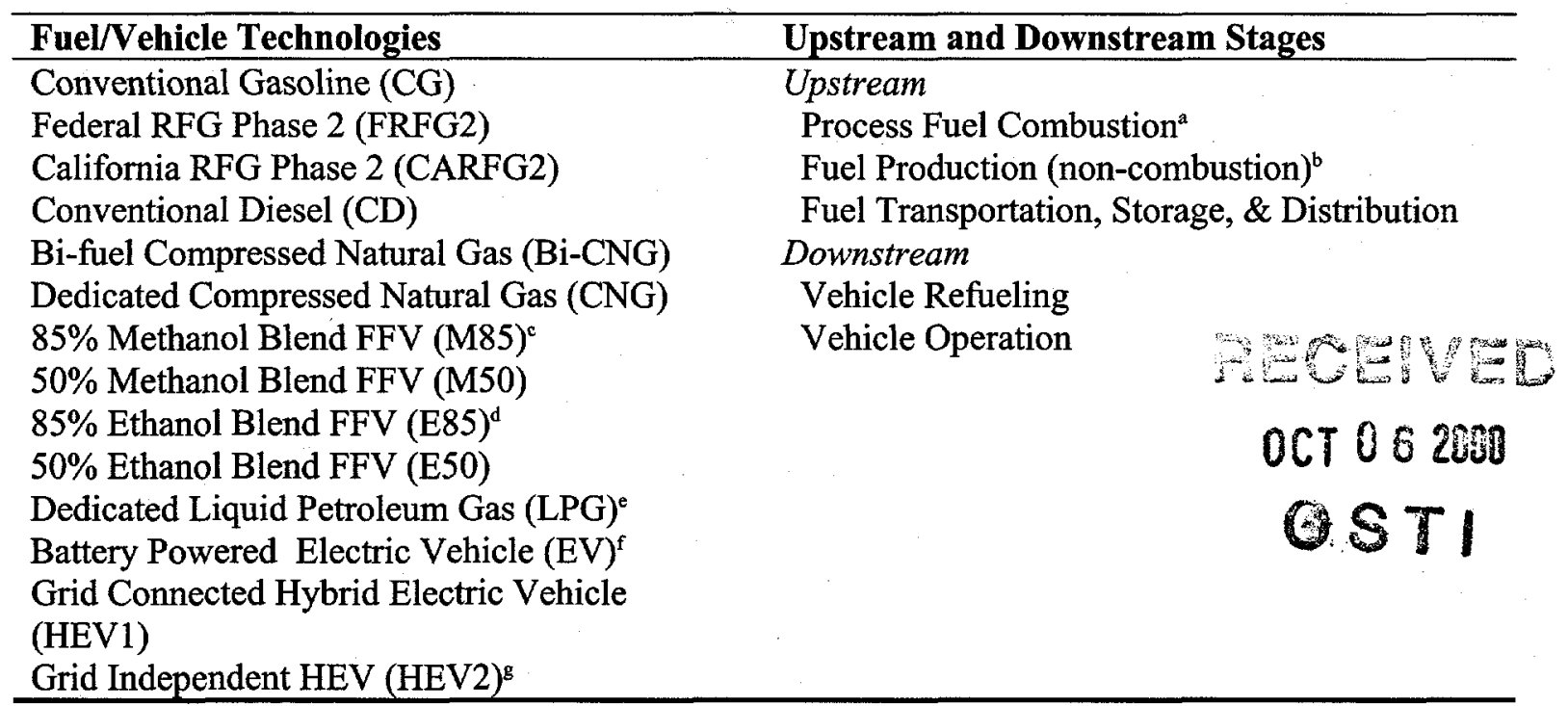

aProcess fuel combustion refers to any fuel burned in the feedstock recovery, fuel production, and transportation, storage, and distribution (TS\&D) of feedstock or fuel. 'Non-combustion fuel production emissions include emissions events such as fugitive emissions and venting at refineries. ${ }^{\circ}$ The analysis is conducted assuming natural gas as the feedstock for methanol. It also assumes that the alcohol vehicles are flexible-fuel vehicles (FFVs) operating on the alternative fuel blend. ${ }^{\mathrm{d}}$ The analysis is conducted assuming corn as the feedstock for ethanol. ${ }^{\circ}$ The analysis is conducted for LPG with both natural gas and crude oil as the feedstock. Currently, $60 \%$ of the LPG consumed in the U.S. originates from natural gas and $40 \%$ originates from crude. ${ }^{\text {T}}$ The analysis is conducted assuming three separate electricity generation mixes: a California mix, a U.S. mix, and a Northeast U.S. mix. See references [2] and [3] for detailed information regarding the characteristics of each mix. ${ }^{3,4}$ For this analysis, we evaluate Grid-Independent HEVs operating with an internal combustion engine fueled by either CD, FRFG2, or CARFG2.

For each of the technologies in Table 1, air toxic emissions are calculated for upstream and downstream processes. Upstream emissions emanate from: fuel combustion that occurs throughout the feedstock recovery and fuel production processes; non-combustion fuel production processes (e.g., emissions from venting during petroleum refining); and transportation, storage, and distribution (TS\&D) of feedstock and fuel. Downstream processes include vehicle fueling and operation.

The next section of the paper provides background information on the mobile source air toxics evaluated in this study. This background section is followed by a discussion of our methodology, our results, and our conclusions. 


\section{BACKGROUND}

\section{Air Toxics and Mobile Sources}

Section 112 of the Clean Air Act Amendments of 1990 tasked the U.S. Environmental Protection Agency (EPA) with regulating 188 hazardous air pollutants that present a "significant risk" to human health. (Actually, the Clean Air Act lists 189 air toxics, but one, caprolactam, was later de-listed). EPA was further assigned to identify those toxic pollutants that "posed the greatest potential threat to public health in the largest number of urban areas". ${ }^{5}$ In its Draft Integrated Urban Air Toxics Strategy, EPA published 33 of the most threatening air toxics for urban areas, listed in Table 2.

Table 2. Air toxics identified by EPA in the Urban Air Toxics Strategy

\begin{tabular}{lll}
\hline Acetaldehyde & Coke oven emissions & Mercury compounds \\
Acrolein & 1,4-dichlorobenzene & Methyl chloride \\
Acrylonitrile & 1,3-dichloropropene & Methylene diphenyl disocynate \\
Arsenic compounds & 2,3,7,8-tetrachlorodibeno-p-dioxin & Methylene chloride \\
Benzene & Ethylene dibromide & Nickel compounds \\
Bis(2-ethylhexyl)phthalate & Ethylene dichloride & Polycyclic organic matter \\
1,3-Butadiene & Ethylene oxide & Propylene dichloride \\
Cadmium compounds & Formaldehyde & Quinoline \\
Carbon tetrachloride & Hydrazine & Tetrachloroethylene \\
Chloroform & Lead compounds & Trichloroethylene \\
Chromium compounds & Manganese compounds & Vinyl chloride \\
\hline
\end{tabular}

Source: Reference [5], Table 1.

Of all air toxics emitted in 1993, EPA estimates that about $24 \%$ were from major stationary sources, $34 \%$ were from area sources, and $42 \%$ were from mobile sources. Of the 33 pollutants identified in Table 2, several have the distinction of being derived primarily from mobile sources. These are highlighted in the table and include the four pollutants of interest for this paper: acetaldehyde, benzene, 1,3-butadiene, and formaldehyde. EPA estimates that $60 \%$ of total benzene emissions, $56 \%$ of butadiene emissions, $39 \%$ of acetaldehyde emissions, and $33 \%$ of formaldehyde emissions are from mobile sources. ${ }^{2,6}$ Similar estimates were made by Rosenbaum et al who demonstrate that $46 \%$ of acetaldehyde, $63 \%$ of benzene, $59 \%$ of butadiene, and $45 \%$ of formaldehyde concentrations found in the ambient environment are from mobile sources. ${ }^{1}$

These mobile source pollutants are either presumed or known carcinogens. The expected numbers of additional annual cancer deaths due to the mobile source contributions of these four pollutants are shown in Table 3, as determined by EPA in a study conducted in $1993 .{ }^{2}$ This table also lists each pollutant's Cancer Unit Risk Estimate (CURE). The CURE represents the increased lifetime cancer risk due to a continuous lifetime (i.e., 70 -year) exposure to a $1.0 \mu \mathrm{g} / \mathrm{m}^{3}$ increase in concentration. ${ }^{7,8}$ For example, the CURE for acetaldehyde implies an increased risk of cancer of $2.2 \times 10^{-6}$ for every $1.0 \mu \mathrm{g} / \mathrm{m}^{3}$ increase in lifetime exposure. These CURE values are taken from the most recent EPA estimates. ${ }^{9}$

Table 3 also includes CURE estimates for diesel particulate matter (PM). Although we do not address diesel PM in this paper, we include it in Table 3 so readers can compare the relative toxicity of diesel PM with the other four pollutants. (Earlier versions of GREET address total fuel cycle PM emissions). ${ }^{3,4}$ Note that CURE values, especially for diesel PM, are uncertain due to dubious potency factors and exposure estimates; for example, recent estimates by the 
California Air Resource Board (CARB) has suggested that CURE values for diesel PM could be more than an order of magnitude higher than previously thought. ${ }^{10}$ Indeed, Woodruff et al. recently published a study on the cancer risk from inhaled HAP based on 1990 exposure estimates, and concluded that polycyclic organic matter (the major carcinogenic constituent in diesel PM) was responsible for $40 \%$ of total estimated lifetime HAP cancer cases. ${ }^{11}$ Butadiene, formaldehyde and benzene were responsible for $17 \%, 8 \%$, and $7 \%$ of these cancer cases, respectively.

Table 3. Cancer Unit Risk Estimate (CURE) and annual expected cancer deaths due to exposure to selected mobile source air toxics.

\begin{tabular}{lccccc}
\hline & \multicolumn{5}{c}{ Annual Expected Cancer Deaths } \\
\hline Pollutant & CURE & 1990 & 1995 & 2000 & 2010 \\
& $\left(\mu \mathrm{g} / \mathrm{m}^{3}\right)^{-1}$ & & & & \\
\hline Acetaldehyde & $2.2 \times 10^{-6}$ & 5.3 & 3.6 & 2.8 & 3.0 \\
Benzene & $8.3 \times 10^{-6}$ & 70 & 43 & 35 & 35 \\
1,3-Butadiene & $2.8 \times 10^{-4}$ & 304 & 209 & 176 & 204 \\
Formaldehyde & $1.3 \times 10^{-5}$ & 44 & 28 & 21 & 22 \\
Total: four air toxics & & $\mathbf{4 2 3}$ & $\mathbf{2 8 3}$ & $\mathbf{2 3 5}$ & $\mathbf{2 6 4}$ \\
Diesel PM $^{\mathrm{a}}$ & $1.7 \times 10^{-5}$ & 109 & 66 & 39 & 27 \\
Diesel PM $^{\text {b }}$ & $3.0 \times 10^{-4}$ & 1,923 & 1,165 & 688 & 476 \\
\hline
\end{tabular}

Source: Reference [2] using Base Case analysis results. ${ }^{2}$ The diesel PM CURE is from EPA, reference [2]. ${ }^{6}$ This diesel PM CURE is from CARB, reference [10]. Expected cancer deaths for CARB CURE data are calculated by multiplying EPA annual death estimates by the ratio of CARB CURE to EPA CURE.

\section{Air Toxic Descriptions}

Each of the toxic air pollutants studied in this paper are either known or probable human carcinogens. A detailed description of each of the air toxics is beyond the scope of this paper, but such information can be found on EPA's IRIS database. ${ }^{9}$ For the purpose of this paper, we present a brief description of each air toxic. Note that emissions inventory data presented below are from EPA's 1999 inventory effort aimed at identifying 1990 emissions levels. ${ }^{12}$ Since 1990 , new fuel formulations and regulations have undoubtedly reduced total emissions for each of these toxics, possibly by $1 / 3$ to $1 / 2$. It is unclear whether the percent contribution from mobile sources has changed dramatically or not.

\section{Acetaldehyde}

Acetaldehyde $\left(\mathrm{CH}_{3} \mathrm{CHO}\right)$ is a saturated aldehyde that is colorless, volatile, and flammable at room temperature. There is inadequate human data, but sufficient animal data to suggest that acetaldehyde is a probable human carcinogen. In animal studies, rats and hamsters experiencing acetaldehyde inhalation exposure had an increased incidence of nasal and laryngeal tumors. Thus, EPA has identified acetaldehyde as a B2 Probable Human Carcinogen. ${ }^{9}$ Acetaldehyde is largely formed during the incomplete combustion of hydrocarbon based fuels. It is present in tailpipe emissions from both gasoline and diesel vehicles. EPA estimates that on-road vehicles emitted about $26 \%\left(35,300\right.$ tons/yr) of total acetaldehyde in $1990 .^{12}$

\section{Benzene}

Benzene $\left(\mathrm{C}_{6} \mathrm{H}_{6}\right)$ is a clear, colorless, aromatic hydrocarbon. Its structure, a hexagonal ring of carbon atoms with bonded hydrogen atoms, is a common building block for many other 
chemical species (those in the family of aromatics). Benzene has been found to cause cancer and leukemia in lab animals and human populations subjected to long term exposure. ${ }^{9}$ EPA has classified benzene as a Group A Known Human Carcinogen based on various human epidemiological studies that focused on occupational inhalation exposure. ${ }^{13-15}$

1990 inventory data indicate that the major source of benzene is on-road vehicles, representing over $50 \%$ (209,000 tons/yr) of the total benzene emissions inventory. ${ }^{12}$ Benzene is a volatile component of gasoline and other fuels and is emitted from vehicles as both an exhaust gas and in evaporative emissions. Depending on control technology and fuel type, benzene makes up about $3-5 \%$ of the total organic gas (TOG) exhaust emissions and about $1 \%$ of the evaporative emissions for conventional gasoline vehicles. Exhaust benzene is from either unburned benzene or benzene formed during the combustion of other aromatic and non-aromatic compounds found in gasoline. ${ }^{16}$

Data show that benzene emissions from motor vehicles are predominantly from gasoline vehicles, with diesel vehicles contributing only about $3 \%$ of the total mobile source benzene emissions. ${ }^{17}$ In addition, evaporative emissions of benzene are relatively small compared to exhaust emissions. ${ }^{2}$ Other sources of benzene include biomass combustion, oil and gas production, petroleum refining, and gasoline distribution.

\section{1,3-Butadiene}

Butadiene $\left(\mathrm{C}_{4} \mathrm{H}_{6}\right)$ is a colorless, flammable, aromatic hydrocarbon. (Note that we use the term 1,3-butadiene and butadiene interchangeably throughout this paper). There is inadequate human data (based on only a few occupational exposure studies), but sufficient animal data to suggest that butadiene is a human carcinogen. In animal studies, rats exposed to airborne concentrations of butadiene developed multiple tumor types. In addition, chemical compounds related in structure to butadiene are known carcinogens. Thus, EPA has identified butadiene as a $B 2$ Probable Human Carcinogen. ${ }^{9}$

EPA estimates that based on 1990 data, over $50 \%$ (36,900 tons/year) of butadiene emissions are from the incomplete combustion of fuel in motor vehicles. ${ }^{12}$ Because of low concentrations of butadiene in conventional fuels, the evaporative emissions of butadiene from motor vehicles are assumed to be negligible. ${ }^{2}$

\section{Formaldehyde}

Formaldehyde (HCHO) is the simplest aldehyde and is a colorless gas. EPA has classified formaldehyde as a BI Probable Human Carcinogen. ${ }^{9}$ This classification is based on a limited amount of studies that show some relationship between formaldehyde exposure and lung cancer in humans, and on more definitive studies with rats, mice, and monkeys that show an increase in cancer due to long-term inhalation exposure. In addition, formaldehyde has a structure similar to other carcinogenic aldehydes, such as acetaldehyde.

Formaldehyde arises from a variety of sources, the most prevalent being the incomplete combustion of fuel in motor vehicles. Formaldehyde is both a primary pollutant and a secondary pollutant, since it is also formed through the oxidation of many organic compounds. EPA estimates that on-road motor vehicles contributed approximately $28 \%(97,500$ tons/yr) of the total primary formaldehyde emissions in 1990.

This study focuses on primary HCHO emissions. EPA estimates that about $30 \%$ of HCHO in the atmosphere is from primary emissions, and the other $70 \%$ is from secondary emissions. ${ }^{2}$ Of the 
primary $\mathrm{HCHO}$, EPA estimates that about $28 \%$ is from mobile sources; of the secondary $\mathrm{HCHO}$, EPA estimates that about $35 \%$ is due to mobile sources. In recent exposure assessment work, EPA has only considered primary $\mathrm{HCHO}$, under the assumption that primary $\mathrm{HCHO}$ destruction in the atmosphere is offset by secondary $\mathrm{HCHO}$ formation. ${ }^{17}$ In truth, data on secondary $\mathrm{HCHO}$ formation from mobile sources are uncertain. As better data become available, we will include secondary $\mathrm{HCHO}$ formation in our fuel-cycle analysis.

\section{METHODOLOGY}

\section{Overview}

Total fuel-cycle emissions are usually separated into two components: upstream emissions and downstream emissions. Upstream emissions include emissions from all activities associated with recovering and transporting fuel feedstock, as well as refining, storing, and delivering fuel to refueling stations. We separate upstream activities into two groups: feedstock-related stages and fuel-related stages. Downstream emissions include emissions from vehicle refueling and operation. Downstream activities are also referred to as vehicle operation stages in this paper. These components are shown in Figure 1.

Figure 1. Components of a total fuel cycle.

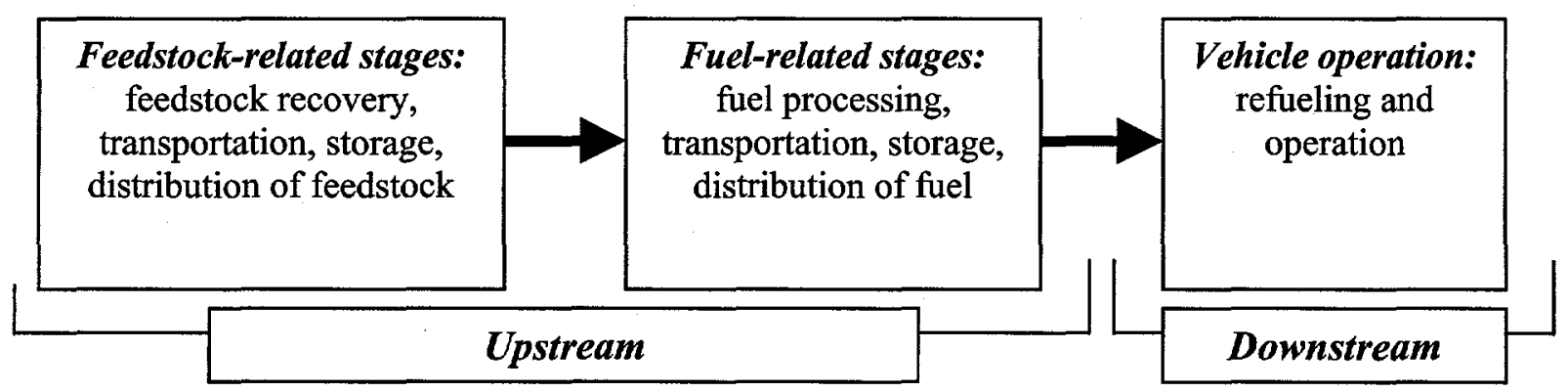

Each stage in the total fuel cycle in Figure 1 includes activities that involve HAP emissions. These emissions are either due to fuel combustion during a particular stage, or non-combustion emissions, such as evaporation during refueling or fugitive emissions at a refinery. The goal of a total fuel cycle analysis is to account for each of the emissions events along the entire fuel cycle chain. In the end we hope to ascertain the total emissions (upstream and downstream) associated with the consumption of a given amount of fuel in the vehicle.

In addition, one must recognize that process fuel consumed at each upstream stage (for example in the energy-intensive activity of petroleum refining) also has its own fuel cycle chain that must be considered. We call these up-upstream processes. Likewise, fuel used to produce the process fuel has an upstream chain associated with it (i.e,. up-up-upstream processes). These upstream chains go on ad infinitum, in what we dub the up ${ }^{\mathrm{n}}$-stream process. Because the amount of fuel used in each chain of the up ${ }^{n}$-stream process grows smaller with each incremental increase in $n$, the emissions values ultimately converge mathematically on a value that captures all the up ${ }^{n}$ stream processes. Figure 2 illustrates this concept for three simplified upstream chains where we only consider fuel use in the fuel production process.

Figure 2. The up ${ }^{\text {n}}$-stream process for $n=3$.
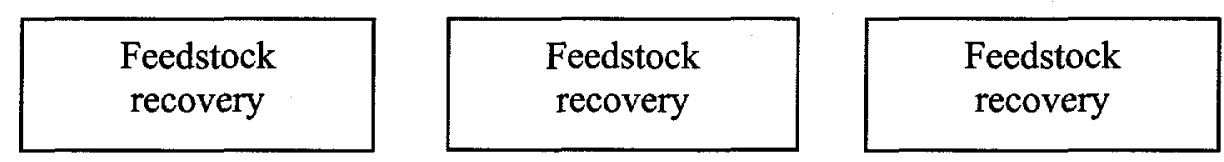


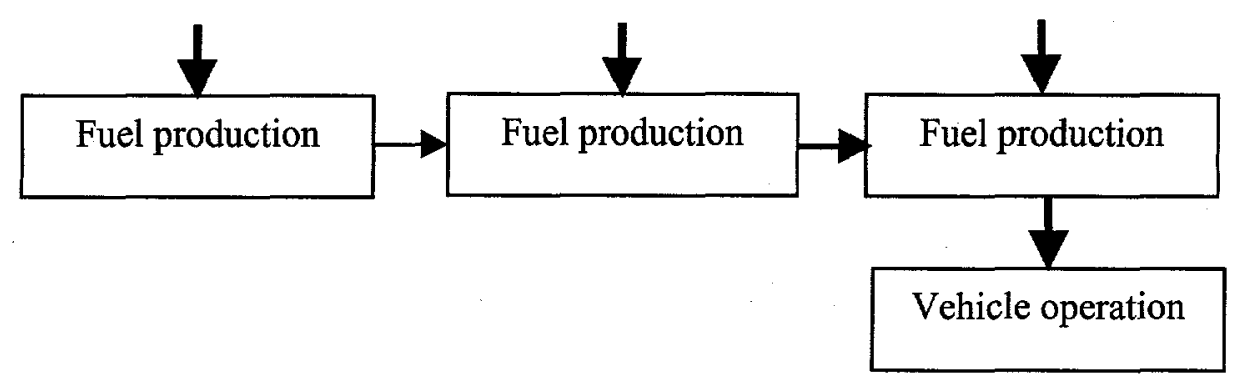

The previously mentioned GREET model can be used to calculate emissions from up $^{\mathrm{n}}$-stream and downstream fuel-cycle stages. It is worthwhile to review GREET's approach in order to better understand the calculations that follow. Much of this discussion is further elaborated in previous work. . $^{3,4}$

GREET calculates Btu per mile (Btu/mi) energy use and grams per mile (g/mi) emissions for different transportation technologies by taking into account energy use and emissions of combustion and non-combustion events in the upstream and downstream stages of the total fuelcycle. The model calculates total energy use (all energy sources), fossil energy use (petroleum, natural gas, and coal), and petroleum use. GREET calculates emissions of three major greenhouse gases (carbon dioxide $\left[\mathrm{CO}_{2}\right]$, methane $\left[\mathrm{CH}_{4}\right]$, and nitrous oxide $\left[\mathrm{N}_{2} \mathrm{O}\right]$ ) and five criteria pollutants (volatile organic compounds [VOCs], carbon monoxide [CO], nitrogen oxides $\left[\mathrm{NO}_{\mathrm{x}}\right]$, particulate matter with aerodynamic diameters 10 microns or less $\left[\mathrm{PM}_{10}\right]$, and sulfur oxides $\left[\mathrm{SO}_{\mathrm{x}}\right]$ ).

Upstream emissions of these pollutants are first calculated in $\mathrm{g} / \mathrm{mmBtu}$ of fuel throughput from each upstream stage. Emissions occurring during a stage include those resulting from the combustion of process fuels and from non-combustion processes such as chemical reactions, fuel leakage, and evaporation.

Emissions from the combustion of process fuels for a particular upstream stage are calculated by using the following formula:

$$
E M_{c m, i}=\left(\sum_{j} \sum_{k} E F_{i, j, k} \times E C_{j, k}\right) \div 1,000,000
$$

where,

$\mathrm{EM}_{c m, i}=$ Combustion emissions of pollutant $i$ in $\mathrm{g} / \mathrm{mmBtu}$ of fuel throughput,

$\mathrm{EF}_{i, j, k}=$ Emission factor of pollutant $i$ for process fuel $j$ with combustion technology $k$ ( $\mathrm{g} / \mathrm{mmBtu}$ of fuel burned), and

$\mathrm{EC}_{j, k}=$ Consumption of process fuel $j$ with combustion technology $k(\mathrm{Btu} / \mathrm{mmBtu}$ of fuel throughput).

$\mathrm{EC}_{j, k}$ for a given stage is, in turn, calculated by using the following formula:

$$
E C_{j, k}=E C \times \text { Share }_{\text {fuelj }} \times \text { Share }_{\text {techk }, j}
$$

where, 


$$
\begin{aligned}
\mathrm{EC}= & \text { Total energy consumption for the given stage (in Btu/mmBtu of fuel } \\
& \text { throughput); } \\
\text { Share }_{\text {fuelj }}= & \text { Share of process fuel } j \text { out of all process fuels consumed during the stage } \\
& \left(\sum_{j} \text { fuel }_{j}=1\right) ; \text { and } \\
\text { Share }_{\text {techk }, j}= & \text { Share of combustion technology } k \text { out of all combustion technologies for fuel } j \\
& \left(\sum_{k} \mathrm{tech}_{k, j}=1\right) .
\end{aligned}
$$

Combustion technology shares (Share techk $_{j}$ ) for a given process fuel are influenced by technology performance, technology costs, and emission regulations for stationary sources. For this study, we assumed combustion technologies and emissions control systems consistent with current conditions.

Therefore, GREET allows for a comprehensive assessment of emissions at all major upstream processes. Adding to these the direct emissions from vehicle operation and refueling activities (expressed in GREET in $\mathrm{g} / \mathrm{mi}$ after applying appropriate energy efficiency estimates) allows one to generate total $\mathrm{g} / \mathrm{mi}$ estimates of the aforementioned pollutants for various transportation technologies.

\section{Upstream Emissions Calculations}

\section{T/VOC Fractions}

In order to calculate upstream emissions for the air toxics in this paper, we evaluate each VOC emissions event in the GREET model and apply a toxic/VOC fraction (T/VOC) to transform that VOC emissions event into a toxic emissions event. (An "emissions event" is any point along the upstream pathway in which VOC emissions occur; the size of the emissions event is a function of fuel type, process technology, and control equipment). T/VOC fractions represent the toxic component of a particular VOC emissions stream. These fractions are specific to each toxic pollutant and emissions event. In the GREET model, the fractions are fixed parameters that are multiplied by VOC emissions levels in order to calculate toxic emissions. This approach is used for the following reasons:

1. Under the assumption that $\mathrm{T} / \mathrm{VOC}$ fractions remain relatively constant as VOC emissions change for a given event, using T/VOC fractions allows us to calculate toxic emissions without having to input new toxic emissions factors every time VOC emissions factors are modified. This approach provides a much more efficient method for conducting sensitivity analysis within the GREET model.

2. Due to data constraints, $\mathrm{T} / \mathrm{VOC}$ fractions are often the only way to estimate toxics for different emissions events. Toxic emissions data are not always available for each individual stationary and mobile source event. However, if T/VOC fractions can be estimated, then we can use these fractions and the relatively more abundant VOC emissions data to determine total toxic emissions. Indeed, this is the approach that EPA uses for many analyses for similar reasons. ${ }^{19}$

3. Using T/VOC fractions allows us to structure the GREET model such that the calculation of toxic emissions is relatively transparent to the user. This benefit will be mostly realized in later work to enhance the user interface for the GREET toxics component. 
The T/VOC approach requires the acquisition of a multitude of data to determine T/VOC fractions for the many different upstream processes modeled in GREET. The three primary data sources we used for both VOC emissions factors and toxic emissions estimates are:

- Factor Information Retrieval (FIRE) Database ${ }^{20}$;

- Compilation of Air Pollutant Emission Factors, (the commonly called AP42 document) ${ }^{21}$, and

- Locating and Estimating Emissions Documents for each of the pollutants (L\&E) ${ }^{22-25}$

\section{Upstream Stages Analyzed}

Upstream stages can be categorized into feedstock processes, which include feedstock extraction and feedstock transportation, storage, and distribution (TS\&D); and fuel processes, which include fuel production and fuel TS\&D. As stated earlier, each upstream process may include combustion and non-combustion emissions. Table 4 provides a list of the primary combustion fuels and technologies that are included in our upstream analysis. (Readers are referred to Wang ${ }^{3,4}$ and Winebrake et $\mathrm{a}^{26}$ for detailed information about these and other processes studied in GREET).

Non-combustion processes primarily include emissions from fuel refining. These emissions emerge in catalytic cracking, process venting, and fugitive emissions. In addition, evaporative emissions from fuel transfer and fuel storage are also considered in our analysis. To calculate these non-combustion emissions, we used the above mentioned databases to calculate toxic emission factors directly. The units for these emissions factors are ultimately converted into $\mathrm{mg} / \mathrm{mmBtu}$ of fuel product throughput. By multiplying these emissions factors by GREET's estimates of product throughput, we are able to calculate total non-combustion toxic emissions directly. 
Table 4. Combustion fuels and technologies included in the GREET analysis.

\begin{tabular}{ll}
\hline Fuel & Technologies \\
\hline Coal & Utility boilers; Industrial boilers \\
\hline Residual oil & $\begin{array}{l}\text { Utility boilers; Industrial boilers; Commercial } \\
\text { boilers; Barge }\end{array}$ \\
\hline Diesel & $\begin{array}{l}\text { Utility boilers and turbines; Industrial boilers and } \\
\text { cogeneration; Commercial boilers and cogeneration; } \\
\text { Locomotive; Heavy-duty truck; Farm tractors }\end{array}$ \\
\hline Natural Gas, LPG, and & $\begin{array}{l}\text { Utility boilers, turbines, and cogeneration; Industrial } \\
\text { boilers, turbines, and cogeneration; Commercial } \\
\text { boilers, turbines, and cogeneration; Flaring }\end{array}$ \\
\hline Gasoline & $\begin{array}{l}\text { Reciprocating engines; Heavy-duty truck; Farm } \\
\text { tractor }\end{array}$ \\
\hline Wood & Fluidized bed combustion; Stoke boilers \\
\hline Transportation fuels & Various transportation technologies \\
\hline
\end{tabular}

${ }^{a}$ Transportation fuels include: aviation gasoline, crude oil, CD, CG, FRFG2, CARFG2, heavy gas oil, jet fuel, jet kerosene, naphtha, and residual fuel oil.

\section{Determining Downstream Emissions}

Downstream emissions refer to those emanating from vehicle operation. Sources of these emissions include vehicle refueling, vehicle tailpipe exhaust emissions, and evaporative emissions from vehicle operation.

Similar to our treatment of upstream emissions discussed in the prior section, we employ T/VOC fractions to calculate downstream air toxic emissions. In this approach, we determine toxic emissions by multiplying a vehicle's estimated downstream VOC emissions by a particular pollutant's T/VOC fraction for that vehicle technology. This is a generally accepted method used recently by EPA. ${ }^{2,9}$ This approach demands that we identify T/VOC fractions for acetaldehyde, benzene, butadiene, and formaldehyde for vehicles operating on the conventional and alternative fuels shown earlier in Table 1. We consider these fuels in conjunction with vehicle technologies currently in existence or expected to exist within the next several years. Analysis of long-term technologies will occur under later phases of this study.

One issue that arose in researching T/VOC fractions for LDVs is the distinction between the following classes of LDVs: LDGV (passenger cars), LDGT1 (light-duty trucks with gross vehicle weigh less than $6,000 \mathrm{lbs}$.), and LDGT2 (light-duty trucks with gross vehicle weight of 6,001 and $8,500 \mathrm{lbs}$.). With respect to RFG, U.S. EPA has shown that the differences in T/VOC fractions among these vehicle types are negligible, varying by hundredths of a percent, if at all. ${ }^{9}$ Therefore, for this study we have chosen to conduct the analysis based on LDGV assumptions. More detailed assessment by vehicle class is reserved for future work.

T/VOC fractions for different AFV classes are even more uncertain. There have been no studies that attempt to distinguish T/VOC fractions among these classes; indeed, there are very few studies that estimate toxic emissions from AFVs. With this dearth of data, we are unable to say 
whether T/VOC fractions from different classes of AFVs would vary significantly. Therefore, similar to conventional vehicles, we assumed calculations of T/VOC fractions for AFVs can be applied equally to the three vehicle classes.

T/VOC fractions for conventional fuels (i.e., gasoline and diesel) were determined based on existing literature and original analysis using EPA's Unconsolidated Complex Model for Reformulated Gasoline. (The "unconsolidated" model separates emissions by control technology type, so the user can identify T/VOC fractions for different control technologies). In recent work, EPA estimated toxic/total organic gas (T/TOG) fractions for various conventional fuel blends using the Complex Model. ${ }^{9}$ For this study we applied the Complex Model to establish T/VOC fractions for CG, FRFG2, and CARFG2. The fuel attributes for our fuels are shown in Table 5. These attributes also act as input parameters in the Complex Model.

Table 5. Fuel parameters for conventional fuels studied.

\begin{tabular}{lccc}
\hline Parameter & CG & FRFG2 & CARFG2 \\
\hline Oxygenate $\left(\mathrm{O}_{2} \% \mathrm{wt}\right)^{\mathrm{a}}$ & $0.4^{\mathrm{a}}$ & $2.7^{\mathrm{a}}$ & $2.1^{\mathrm{b}}$ \\
Sulfur (ppm) & 200 & 30 & 30 \\
$\mathrm{RVP}(\mathrm{psi})$ & 8.7 & 8.7 & 6.8 \\
E200 (\%) & 41 & 41 & 41 \\
E300 (\%) & 83 & 83 & 83 \\
Aromatics (\%) & 28.6 & 23.4 & 22 \\
Olefins (\%) & 10.8 & 8.2 & 4 \\
Benzene (\%) & 1.6 & 1.0 & 0.8 \\
\hline${ }^{\mathrm{a}}$ Oxygenate in this case is MTBE. ${ }^{\mathrm{b}}$ Oxygenate in this case is ETBE.
\end{tabular}

Using these fuel blends, T/VOC fractions were determined assuming three-way catalytic converter technology with fuel injection (3WPFI). (EPA expects 100\% of LDVs and over $90 \%$ of LDGTs sold in year 2001 to be of this type). ${ }^{9}$ All T/VOC estimates are for tailpipe exhaust emissions, except for benzene, in which exhaust and evaporative fractions were determined. Evaporative fractions for benzene are include hot soak, diurnal, running loss, and refueling emissions.

For AFVs, we relied on existing data and published research on toxic emissions from these types of vehicles. Table 6 shows the T/VOC fractions that were determined for each of the fuels studied. The notes under the table identify data sources. A more complete discussion of data sources is included in Winebrake et al. ${ }^{26}$

\section{RESULTS}

\section{Summary of Results}

Our results are presented as per mile emissions on a fuel-by-fuel comparison for each of the toxic pollutants. Table 7 shows emissions in grams $/ \mathrm{mile}$ (for VOC) and $\mathrm{mg} / \mathrm{mile}$ (for toxics) for each of three fuel-cycle stages analyzed in this study. The Feedstock stage refers to the combustion and non-combustion emissions associated with feedstock recovery and TS\&D. The Fuel stage refers to the combustion and non-combustion emissions associated with fuel production, and TS\&D. Finally, the Vehicle stage refers to emissions from vehicle refueling and operation.

Table 6. T/VOC fractions for downstream emissions. 


\begin{tabular}{|c|c|c|c|c|c|}
\hline \multirow[t]{2}{*}{ Fuel } & \multicolumn{5}{|c|}{ T/VOC Fractions (\%) } \\
\hline & Benzene & Acetaldehyde & Formaldehyde & Butadiene & $\begin{array}{l}\text { Benzene } \\
\text { (Evaporative) }\end{array}$ \\
\hline $\mathrm{CG}^{\mathrm{a}}$ & 3.62 & 0.32 & 0.78 & 0.35 & 1.15 \\
\hline 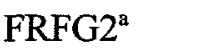 & 2.67 & 0.35 & 1.11 & 0.38 & 0.64 \\
\hline${\text { CARFG } 2^{\mathrm{a}}}$ & 2.55 & 0.75 & 1.03 & 0.35 & 0.71 \\
\hline$C D^{b}$ & 5.09 & 0.53 & 1.29 & 0.67 & 0.00 \\
\hline $\mathrm{Bi}^{\mathrm{C}} \mathrm{CNG}^{\mathrm{c}}$ & 0.20 & 0.46 & 6.21 & 0.05 & 0.00 \\
\hline $\mathrm{CNG}^{\mathrm{c}}$ & 0.20 & 0.46 & 6.21 & 0.05 & 0.00 \\
\hline M85 & 2.00 & 0.35 & 15.00 & 0.35 & 0.17 \\
\hline $\mathrm{M}^{\circ} 0^{\mathrm{e}}$ & 3.30 & 0.50 & 8.00 & 0.40 & 0.58 \\
\hline $\mathrm{E} 85^{\mathrm{f}}$ & 1.30 & 12.70 & 5.20 & 0.20 & 0.17 \\
\hline E50 & 3.70 & 10.00 & 5.10 & 0.30 & 0.58 \\
\hline $\mathrm{LPG}^{\mathrm{g}}$ & 0.41 & 0.36 & 1.17 & 0.08 & 0.00 \\
\hline$E V^{h}$ & 0.00 & 0.00 & 0.00 & 0.00 & 0.00 \\
\hline HEV1 & 0.00 & 0.00 & 0.00 & 0.00 & 0.00 \\
\hline HEV2 & 0.00 & 0.00 & 0.00 & 0.00 & 0.00 \\
\hline
\end{tabular}

${ }^{a}$ Results from EPA Complex Model. ${ }^{b}$ Reference [9], Appendix C. ${ }^{\mathrm{C}} \mathrm{Bi}-\mathrm{CNG}$ fractions are for operation on CNG. Data from reference [27]; values are lower than those in reference [28], but consistent with EPA and CARB estimates. ${ }^{29 .}$ ${ }^{31} \mathrm{~d}$ M85 data from reference [27], adjusted downward based on evidence in other studies. ${ }^{28,32,33-36}$ Evaporative emissions assumed to be from gasoline in the alcohol blends. ${ }^{\mathrm{C}} \mathrm{M} 50$ and E50 values based on AFDC data, using similar analysis as in reference [27]. fData based on reference [27]; results are consistent with other studies. ${ }^{29,34,36}$ ${ }^{9}$ Based on AFDC data, using similar analysis as in reference [27]; results are consistent with other studies. ${ }^{30,34}$ bVV, HEV1, and HEV2 will have no toxic tailpipe emissions. HEVs operating in conjunction with RFG internal combustion engines will have T/VOC fractions identical to the RFG blends discussed above.

Note that upstream stages (Feedstock and Fuel) contain many upstream activities, each contributing to the per-mile values shown. This fact alleviates some apparent contradictions that appear in the table. For example, consider ethanol fuel blends: because ethanol plants produce animal feeds together with ethanol, emission credits from produced animal feeds are calculated with the so-called "displacement method." ${ }^{37}$ Thus, corn-based ethanol gains a "VOC-credit" represented by a negative VOC value in the table; however, the T/VOC fractions for these creditgenerating activities are quite small, while the fractions are large for other upstream Feedstock activities. Thus, the Feedstock stage for ethanol shows an overall VOC-credit, while still demonstrating positive toxic emissions.

Figures 3 through 7 depict per mile, fuel-cycle emissions for each pollutant and fuel type relative to conventional gasoline. These figures can be used to better understand the potential impact that reformulated gasoline and alternative fuels will have on total toxic emissions. Although these figures were derived from the analysis of passenger cars, we predict that similar results will also hold true for LDTs, although more research is needed in this area. Each figure is discussed in its respective section below.

\section{VOC Results}

As shown in Figure 3, per-mile VOC emission results indicate a noticeable reduction in VOCs using reformulated and alternative fuels. Total VOC estimates are lower relative to conventional gasoline for all fuels studied, except ethanol blends. Ethanol vehicles tend to have higher total VOC emissions due to emissions related to the fuel production stage of the total fuel-cycle. As seen in Table 7, VOC emissions from ethanol fuel production are actually higher than emissions from vehicle operation. As expected, FRFG2 and CARFG2 show 10\%-18\% lower VOC 
emissions, and the gaseous fuels show reductions of 50\%-60\%. These significant reductions are largely due to vehicle operation characteristics, as the gaseous fuels have 2-4 times less VOC emissions in this stage when compared to CG.

\section{Formaldehdye Results}

Figure 4 depicts significant variation in $\mathrm{HCHO}$ emissions depending on the fuel selected. The first noticeable difference is the extremely large increase in HCHO for methanol vehicles. These emissions differences are primarily due to vehicle operation, where $\mathrm{HCHO}$ emissions are over six times higher for M85 vehicles as compared to CG vehicles. The same is true for ethanol vehicles and $\mathrm{CNG}$ vehicles, in which $\mathrm{HCHO}$ from vehicle operation is much larger than for $\mathrm{CG}$ vehicles.

Note that $\mathrm{HCHO}$ emissions in this case are primary $\mathrm{HCHO}$ emission, and do not include $\mathrm{HCHO}$ formed as a secondary pollutant in the atmosphere due to VOCs emitted from these vehicles. As discussed earlier, EPA has estimated that up to $40 \%$ of $\mathrm{HCHO}$ in the atmosphere may be due to secondary $\mathrm{HCHO}$ formation. Because $\mathrm{CG}$ vehicles have higher VOC emissions than M50, M85, CNG, and LPG, we would expect secondary HCHO from CG vehicles to be higher than from these alternatives. Interestingly, even the reformulated gasoline fuels show significantly higher HCHO emissions, due to a combination of the fuel production process and the combustion products of their oxygenate additives (ETBE and MTBE).

\section{Acetaldehyde Results}

Figure 5 depicts changes in per-mile, fuel-cycle acetaldehyde emissions relative to conventional gasoline. The most substantial increase comes from ethanol vehicles, which have very high acetaldehyde tailpipe emissions. As shown in Table 7, downstream acetaldehyde emissions from ethanol vehicles are over 30 times higher than CG vehicles. In addition, upstream acetaldehyde emissions from ethanol production are five times greater than for CG production.

The reformulated fuels (CARFG2 and FRFG2) also exhibit higher acetaldehyde emissions, primarily due to the production and combustion of their oxygenates (ETBE and MTBE, respectively). As expected, ETBE causes almost a doubling of acetaldehyde emissions relative to gasoline. The gaseous fuels show modest reductions in acetaldehyde emissions, for although their acetaldehyde T/VOC fractions are higher than CG, their total VOC emissions are lower and thus cancel out these higher fractions. Electric vehicles, due to the relative elimination of VOCs in the entire fuel-cycle, show the largest acetaldehyde reductions of all the alternatives.

\section{Butadiene Results}

Figure 6 shows that butadiene emissions are typically lower for all the alternatives relative to $\mathrm{CG}$, except for diesel fuels, ethanol fuels, and CARFG2. Diesel fuels have downstream T/VOC fractions for butadiene that are almost twice as high as CG. Ethanol fuels also exhibit higher butadiene emissions, although these emerge from upstream processes in the feedstock and fuel production stages of the fuel-cycle. Similarly, CARFG2 shows slightly higher butadiene emissions due to the fuel production stage of the fuel-cycle. Finally, because of the virtual elimination of butadiene in the vehicle operations stage of the fuel-cycle for gaseous fuels, there are significant reductions found for LPG and CNG vehicles. 


\section{Benzene Results}

As seen in Figure 7, all fuels demonstrate significantly lower benzene emissions, with electric vehicles, LPG vehicles, and CNG vehicles achieving close to a 100\% reduction. E85 and M85 blends achieve greater than 60\% reductions, with E50 and M50 showing higher emissions due to the gasoline in their blends. The reformulated fuels (FRFG2 and CARFG2) show decreases as well, primarily due to lower concentrations of benzene in their fuel formulations.

\section{CONCLUSION}

This paper presents the results of an analysis to determine total fuel-cycle emissions of toxic pollutants from conventional and alternative fuel vehicles. There are several issues reserved for future work. These issues include:

- Addressing data quality concerns. Although we have derived our T/VOC fractions from the best available data, there are still areas for improvement. Some upstream processes do not have explicit data for toxic emissions, and so assumptions had to be made where appropriate (see Winebrake et al for detailed assumptions). ${ }^{27}$ In addition, downstream emission factors, especially for AFVs, have only recently been studied in depth. As new studies emerge, we must revise our T/VOC fractions as appropriate.

- Addressing long-term vehicle technologies. This study considers near-term technologiesthose currently in existence or expected to be in existence in the next few years. However, advancements in vehicle technology and emissions control systems may significantly alter our results when considered over a longer time horizon (e.g., 10-15 years out). One must keep this consideration in mind if attempting to apply our results to future transportation scenarios.

- Addressing exposure issues. This study determines emissions of toxic pollutants over the total fuel-cycle for various transportation alternatives. These emissions should not be confused with actual human exposure to these toxic pollutants, or with the actual carcinogenic risk of each fuel. To determine the relative health impacts of various fuelcycles, one would need to apply our emissions results to an exposure model that captures exposure population, location, duration, and potency. This issue is most glaring when considering the seemingly problematic toxic emissions associated with ethanol vehicles. One should recognize that much of the upstream emissions from ethanol production occur in rural areas, where exposed populations are much smaller than in urban areas (where downstream emissions primarily occur).

Despite these issues, we believe this study provides a useful understanding of toxic emissions for alternative and conventional fuels. The results from this study can be used to more clearly decipher the potential impacts of recent movements toward the use of AFVs. 
Table 7. Estimated per-mile air toxic emissions ( $\mathrm{g} / \mathrm{mile}$ for $\mathrm{VOC}$ and $\mathrm{mg} / \mathrm{mile}$ for toxics)

\begin{tabular}{|c|c|c|c|c|c|c|}
\hline \multirow[b]{2}{*}{ Vehicle } & \multirow[b]{2}{*}{ Stage } & \multicolumn{5}{|c|}{ Pollutant } \\
\hline & & $\begin{array}{l}\text { VOC } \\
(\mathrm{g} / \mathrm{mi})\end{array}$ & $\begin{array}{l}\text { Formaldehyde } \\
(\mathrm{mg} / \mathrm{mi})\end{array}$ & $\begin{array}{l}\text { Acetaldehyde } \\
(\mathrm{mg} / \mathrm{mi})\end{array}$ & $\begin{array}{l}\text { Butadiene } \\
\text { (mg/mi) }\end{array}$ & $\begin{array}{l}\text { Benzene } \\
(\mathrm{mg} / \mathrm{mi})\end{array}$ \\
\hline \multirow{4}{*}{ CG } & Feedstock & 0.017 & 0.246 & 0.050 & 0.004 & 0.212 \\
\hline & Fuel & 0.072 & 0.734 & 0.120 & 0.071 & 1.508 \\
\hline & Vehicle & 0.207 & 0.624 & 0.256 & 0.280 & 4.357 \\
\hline & Total & 0.296 & 1.605 & 0.426 & 0.356 & 6.076 \\
\hline \multirow{4}{*}{ FRFG2 } & Feedstock & 0.017 & 0.246 & 0.050 & 0.004 & 0.212 \\
\hline & Fuel & 0.072 & 0.871 & 0.152 & 0.073 & 1.091 \\
\hline & Vehicle & 0.161 & 0.799 & 0.252 & 0.274 & 2.491 \\
\hline & Total & 0.250 & 1.916 & 0.454 & 0.350 & 3.794 \\
\hline \multirow{4}{*}{ CARFG2 } & Feedstock & 0.017 & 0.246 & 0.050 & 0.004 & 0.212 \\
\hline & Fuel & 0.101 & 1.240 & 0.231 & 0.125 & 1.131 \\
\hline & Vehicle & 0.161 & 0.742 & 0.540 & 0.252 & 2.467 \\
\hline & Total & 0.279 & 2.228 & 0.821 & 0.381 & 3.811 \\
\hline \multirow{4}{*}{$\mathrm{CD}$} & Feedstock & 0.013 & 0.182 & 0.037 & 0.003 & 0.157 \\
\hline & Fuel & 0.021 & 0.441 & 0.075 & 0.043 & 0.489 \\
\hline & Vehicle & 0.080 & 1.032 & 0.424 & 0.536 & 4.072 \\
\hline & Total & 0.114 & 1.656 & 0.536 & 0.582 & 4.718 \\
\hline \multirow{4}{*}{$\mathrm{Bi}-\mathrm{CNG}$} & Feedstock & 0.018 & 1.414 & 0.181 & 0.006 & 0.157 \\
\hline & Fuel & 0.011 & 0.779 & 0.096 & 0.006 & 0.044 \\
\hline & Vehicle & 0.112 & 2.981 & 0.221 & 0.024 & 0.096 \\
\hline & Total & 0.140 & 5.174 & 0.498 & 0.035 & 0.296 \\
\hline \multirow{4}{*}{$\mathrm{CNG}$} & Feedstock & 0.017 & 1.369 & 0.175 & 0.005 & 0.152 \\
\hline & Fuel & 0.010 & 0.754 & 0.092 & 0.006 & 0.042 \\
\hline & Vehicle & 0.045 & 1.987 & 0.147 & 0.016 & 0.064 \\
\hline & Total & 0.072 & 4.110 & 0.415 & 0.027 & 0.258 \\
\hline \multirow{4}{*}{ LPG: Crude } & Feedstock & 0.017 & 0.246 & 0.050 & 0.004 & 0.212 \\
\hline & Fuel & 0.027 & 0.693 & 0.140 & 0.061 & 0.431 \\
\hline & Vehicle & 0.077 & 0.749 & 0.230 & 0.051 & 0.262 \\
\hline & Total & 0.121 & 1.688 & 0.420 & 0.117 & 0.905 \\
\hline \multirow{4}{*}{ LPG: Natural Gas } & Feedstock & 0.006 & 0.339 & 0.057 & 0.003 & 0.110 \\
\hline & Fuel & 0.023 & 0.595 & 0.137 & 0.045 & 0.074 \\
\hline & Vehicle & 0.077 & 0.749 & 0.230 & 0.051 & 0.262 \\
\hline & Total & 0.106 & 1.682 & 0.424 & 0.099 & 0.446 \\
\hline \multirow{4}{*}{ M50 } & Feedstock & 0.013 & 0.277 & 0.052 & 0.004 & 0.178 \\
\hline & Fuel & 0.066 & 0.669 & 0.112 & 0.059 & 1.037 \\
\hline & Vehicle & 0.199 & 5.760 & 0.360 & 0.288 & 3.186 \\
\hline & Total & 0.278 & 6.706 & 0.524 & 0.356 & 4.401 \\
\hline \multirow{4}{*}{ M85 } & Feedstock & 0.009 & 0.314 & 0.055 & 0.003 & 0.137 \\
\hline & Fuel & 0.058 & 0.589 & 0.101 & 0.044 & 0.457 \\
\hline & Vehicle & 0.176 & 10.200 & 0.238 & 0.238 & 1.544 \\
\hline & Total & 0.242 & 11.103 & 0.394 & 0.290 & 2.138 \\
\hline
\end{tabular}


Table 7. Continued

\begin{tabular}{|c|c|c|c|c|c|c|}
\hline \multirow[b]{2}{*}{ Vehicle } & \multirow[b]{2}{*}{ Stage } & \multicolumn{5}{|c|}{ Pollutant } \\
\hline & & $\begin{array}{c}\text { VOC } \\
(\mathrm{g} / \mathrm{mi})\end{array}$ & $\begin{array}{l}\text { Formaldehyde } \\
(\mathrm{mg} / \mathrm{mi})\end{array}$ & $\begin{array}{l}\text { Acetaldehyde } \\
(\mathrm{mg} / \mathrm{mi})\end{array}$ & $\begin{array}{l}\text { Butadiene } \\
(\mathrm{mg} / \mathrm{mi})\end{array}$ & $\begin{array}{l}\text { Benzene } \\
\text { (mg/mi) }\end{array}$ \\
\hline \multirow{4}{*}{ E50 } & Feedstock & -0.039 & 0.959 & 0.282 & 0.152 & 0.343 \\
\hline & Fuel & 0.235 & 1.468 & 0.204 & 0.133 & 1.032 \\
\hline & Vehicle & 0.199 & 3.672 & 7.200 & 0.216 & 3.474 \\
\hline & Total & 0.395 & 6.099 & 7.687 & 0.515 & 4.844 \\
\hline \multirow{4}{*}{ E85 } & Feedstock & -0.094 & 1.662 & 0.511 & 0.298 & 0.473 \\
\hline & Fuel & 0.396 & 2.192 & 0.287 & 0.193 & 0.563 \\
\hline & Vehicle & 0.176 & 3.536 & 8.636 & 0.136 & 1.068 \\
\hline & Total & 0.478 & 7.390 & 9.435 & 0.651 & 2.092 \\
\hline \multirow{4}{*}{ EV: US Mix } & Feedstock & 0.028 & 0.710 & 0.078 & 0.045 & 0.124 \\
\hline & Fuel & 0.006 & 0.073 & 0.064 & 0.002 & 0.094 \\
\hline & Vehicle & 0.000 & 0.000 & 0.000 & 0.000 & 0.000 \\
\hline & Total & 0.034 & 0.783 & 0.142 & 0.047 & 0.217 \\
\hline \multirow{4}{*}{$\begin{array}{l}\text { EV: Northeast } \\
\text { Mix }\end{array}$} & Feedstock & 0.020 & 0.775 & 0.095 & 0.026 & 0.126 \\
\hline & Fuel & 0.006 & 0.127 & 0.071 & 0.004 & 0.055 \\
\hline & Vehicle & 0.000 & 0.000 & 0.000 & 0.000 & 0.000 \\
\hline & Total & 0.026 & 0.902 & 0.166 & 0.030 & 0.181 \\
\hline \multirow{4}{*}{$\begin{array}{l}\text { EV: California } \\
\text { Mix }\end{array}$} & Feedstock & 0.009 & 0.450 & 0.057 & 0.010 & 0.070 \\
\hline & Fuel & 0.003 & 0.074 & 0.041 & 0.001 & 0.018 \\
\hline & Vehicle & 0.000 & 0.000 & 0.000 & 0.000 & 0.000 \\
\hline & Total & 0.012 & 0.525 & 0.098 & 0.011 & 0.089 \\
\hline \multirow{4}{*}{$\begin{array}{l}\text { HEV1: CA Mix, } \\
\text { CARFG2 }\end{array}$} & Feedstock & 0.009 & 0.231 & 0.037 & 0.005 & 0.104 \\
\hline & Fuel & 0.040 & 0.505 & 0.102 & 0.049 & 0.446 \\
\hline & Vehicle & 0.104 & 0.519 & 0.378 & 0.176 & 1.664 \\
\hline & Total & 0.153 & 1.255 & 0.517 & 0.230 & 2.213 \\
\hline \multirow{4}{*}{ HEV2: FRFG2 } & Feedstock & 0.009 & 0.130 & 0.026 & 0.002 & 0.112 \\
\hline & Fuel & 0.038 & 0.458 & 0.080 & 0.038 & 0.574 \\
\hline & Vehicle & 0.148 & 0.799 & 0.252 & 0.274 & 2.410 \\
\hline & Total & 0.195 & 1.387 & 0.358 & 0.314 & 3.096 \\
\hline \multirow{4}{*}{ HEV2: CD } & Feedstock & 0.009 & 0.123 & 0.025 & 0.002 & 0.106 \\
\hline & Fuel & 0.014 & 0.298 & 0.051 & 0.029 & 0.330 \\
\hline & Vehicle & 0.080 & 1.032 & 0.424 & 0.536 & 4.072 \\
\hline & Total & 0.103 & 1.453 & 0.500 & 0.567 & 4.508 \\
\hline
\end{tabular}


Figures 3-7. Changes in total fuel cycle emissions for various fuels compared to conventional gasoline.
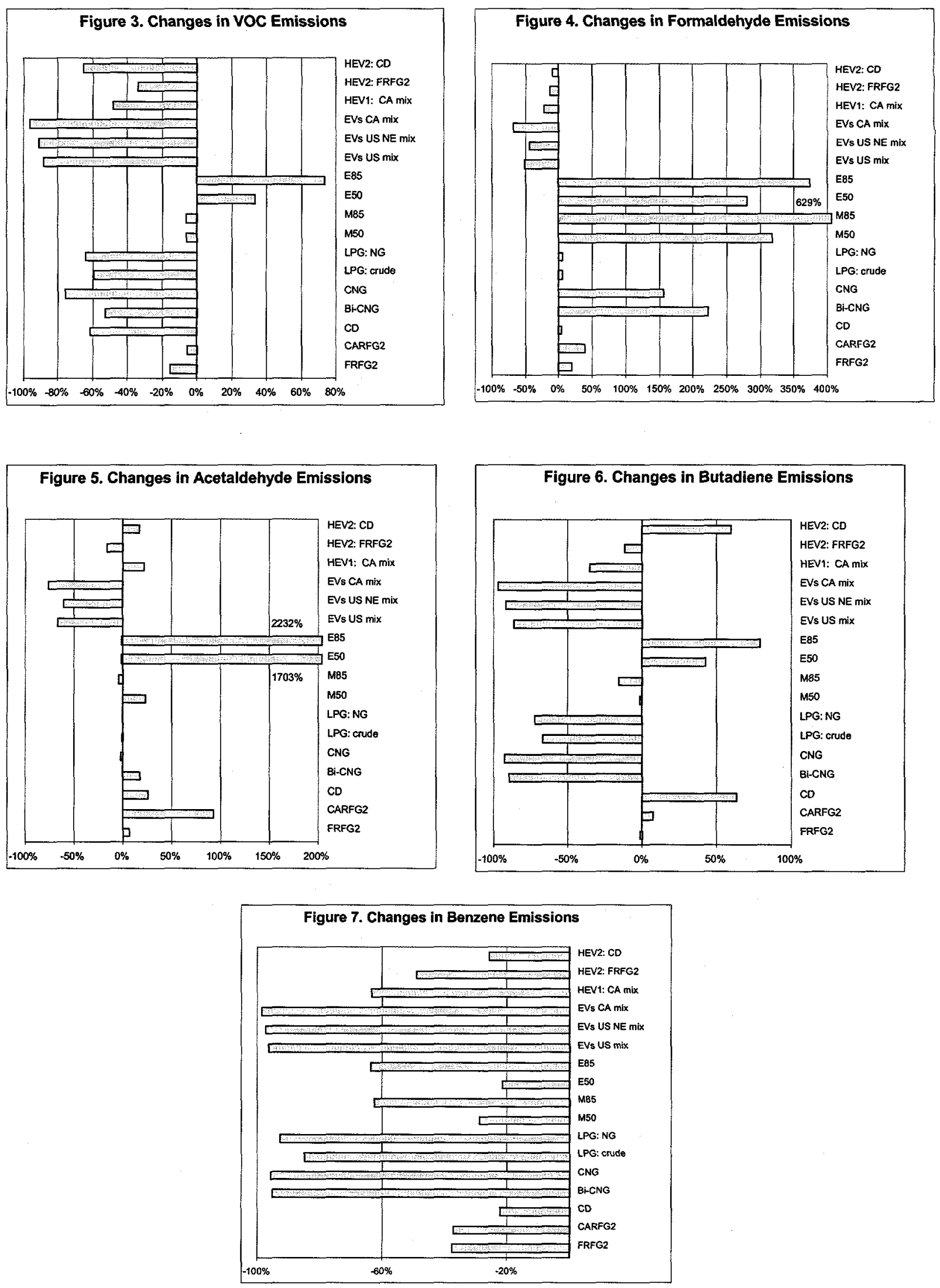


\section{ACKNOWLEDGMENTS}

We would like to thank Paul McArdle of Office of Technology Utilization within the Office of Transportation Technologies of the U.S. Department of Energy, for funding this study. We also thank Richard Cook of the U.S. Environmental Protection Agency, Phil Heirigs of Sierra Research, and Ed Carr of ICF Consulting for their advice, data, and insights into urban air toxics and EPA's regulatory models. The authors are solely responsible for the content and accuracy of the paper.

\section{REFERENCES}

1. Rosenbaum, A.S., D.A. Axelrad, T.J. Woodruff, Y.Wei, M.P. Ligocki, and J.P. Cohen, 1999, "National Estimates of Outdoor Air Toxic Concentrations," Journal of the Air and Waste Management Association, 49:1138-1152.

2. U.S. Environmental Protection Agency (EPA), 1993, Motor-Vehicle Related Air Toxics Study, Office of Mobile Sources, Ann Arbor, MI, EPA420-D-99-002a, March.

3. Wang, M., 1999, GREET 1.5 - Transportation Fuel-Cycle Model: Volume 1, Methodologies, Development, and Use, ANL/ESD-39, Vol.1, Center for Transportation Research, Argonne National Laboratory, Argonne, IL, August.

4. Wang, M. Q., 1999, GREET1.5 -- Transportation Fuel Cycle Model, Volume 2: Detailed Assumptions and Results, ANL/ESD-39, Vol. 2, Center for Transportation Reseat, Argonne National Laboratory, Argonne, IL, August.

5. U.S. Environmental Protection Agency (EPA), 1998, "Draft Integrated Urban Air Toxics Strategy to Comply with Section 112(k), 112(c)(3), and section 202(1) of the Clean Air Act," Federal Register, Vol. 63, No. 177, September 14, 1998, pp.49240-49258.

6. U.S. Environmental Protection Agency (EPA), 1999, Indicators of the Environmental Impacts of Transportation, Office of Policy, Washington, DC, EPA230-R-99-001, October.

7. Calabrese, E.J. and E.M. Kenyon, 1991, Air Toxics and Risk Assessment, Lewis Publishers, Michigan.

8. Gratt, L.B., 1996, Air Toxic Risk Assessment and Management, Van Nostrand Reinhold. New York, NY.

9. U.S. Environmental Protection Agency (EPA), 1999, Integrated Risk Information System, Office of Health and Environmental Assessment, Environmental Criteria and Assessment Office, Cincinnati, $\mathrm{OH}$.

10. California Air Resources Board (CARB), 1998, Findings fo the Scientific Review Panal on the Report of Diesel Exhaust, Sacramento, California, April 22.

11. Woodruff, R.J., J. Caldwell, V.J. Cogliano and D.A. Axelrod, 2000, “Estimating Cancer Risk from Outdoor Concentrations of Hazardous Air Pollutants in 1990," Environmental Research Section A, 82:194-206.

12. U.S. Environmental Protection Agency (EPA), 1999, 1990 Emissions Inventory of Forty Potential Section 112(k) Pollutants: Supporting Data for EPA's Section 112(k) Regulatory 
Strategy, Final Report, Emissions Factors and Inventory Group and Emissions Standards Division, Research Triangle Park, NC, May 21.

13. Rinsky, R.A., R.J. Young and A.B. Smith, 1981, "Leukemia in Benzene Workers," Am. J. Ind. Med., 2:217-245.

14. Wong, O., R.W. Morgan and M.D. Whorton, 1983, Comments on the NIOSH Study of Leukemia in Benzene Workers, Technical report submitted to Gulf Canada, Ltd., by Environmental Health Associates.

15. Ott, M.G., J.C. Townsend, W.A. Fishbeck, and R.A. Langner, 1978, "Mortality Among Individuals Occupationally Exposed to Benzene," Arch. Environ. Health., 33:3-10.

16. U.S. Environmental Protection Agency (EPA), 1988, Locating and Estimating Air Emissions from Sources of Benzene, Office of Air Quality Planning and Standards, Research Triangle Park, NC: EPA-450/4-84-007q.

17. Carey, P.M., 1987, Air Toxics Emissions from Motor Vehicles, U.S. Environmental Protection Agency, Office of Mobile Sources, EPA-AA-TSS-PA-86-5, Ann Arbor, MI.

18. Cook, R., 1999, personal communication, December 7, 1999.

19. U.S. Environmental Protection Agency (EPA), 1999, Estimation of Motor Vehicle Toxic Emissions and Exposure in Selected Urban Areas, DRAFT, EPA420-D-99-002a, Assessment and Modeling Division, Office of Mobile Sources, Ann Arbor, MI.

20. U.S. Environmental Protection Agency (EPA), 1998, FIRE Version 6.1. Office of Air Quality Planning and Standards, Research Triangle Park. NC, August.

21. U.S. Environmental Protection Agency (EPA), 1995, Compilation of Air Pollutant Emission factors, Volume I, Fifth Edition, AP-42, Office of Air Quality Planning and Standards, Research Triangle Park, NC, January.

22. U.S. Environmental Protection Agency (EPA), 1996, Locating and Estimating Air Emissions from Sources of 1,3-Butadiene, EPA-454/R-96-008, Office of Air Quality Planning and Standards, Research Triangle Park, NC.

23. U.S. Environmental Protection Agency (EPA), 1988, Locating and Estimating Air Emissions from Sources of Benzene, Office of Air Quality Planning and Standards, Research Triangle Park, NC: EPA-450/4-84-007q.

24. U.S. Environmental Protection Agency (EPA), 1998, Locating and Estimating Air Emissions from Sources of Benzene, Office of Air Quality Planning and Standards, Research Triangle Park. NC, June.

25. U.S. Environmental Protection Agency (EPA), 1991, Locating and Estimating Air Emissions From Sources of Formaldehyde (Revised), Office of Air Quality, Research Triangle Park, NC, EPA-450/4-91-012, March.

26. Winebrake, J.J., M. Wang, and D. He, 2000, Fuel-Cycle Emissions for Conventional and Alternative Fuel Vehicles: An Assessment of Air Toxics (DRAFT), Center for Transportation Research, Argonne National Laboratory, Argonne, IL, February. 
27. Winebrake, J.J. and M.L. Deaton, 1999, "Hazardous Air Pollution from Mobile Sources: A Comparison of Reformulated and Alternative Fuel Vehicles," Journal of the Air and Waste Management Association, 49:576-581.

28. Black, F., S. Tejada, and M. Gurevich, 1998, "Alternative Fuel Motor Vehicle Tailpipe and Evaporative Emissions Composition and Ozone Potential," Journal of the Air and Waste Management Association, 48:578-591.

29. U.S. Environmental Protection Agency (EPA), 1990, Analysis of Economic and Environmental Effects of Ethanol as an Automotive Fuel, Office of Mobile Sources, Ann Arbor, MI.

30. California Air Resources Board (CARB), 1989, Definition of a Low-Emission Motor Vehicle in Compliance with the Mandates of Health and Safety Code Section 39037.05. Assembly Bill 234, Leonard, 1987, CARB Mobile Source Division, El Monte, CA.

31. California Air Resources Board (CARB) 1991, Butadiene Emissions Factors, memo from K.D. Drachand to Terry McGuire and Peter Benturini, July 17.

32. Kelly, K.J., B.K. Bailey, T.C. Coburn, W. Clark, L. Eudy, and P. Lissiuk, 1996, FTP Emissions Test Results from Flexible-Fuel Methanol Dodge Spirits and ford Econoline Vans, SAE Technical Paper 961090.

33. Durbin, T., J.R. Collins, J.M. Norbeck, and M.R. Smith, 1999, Evaluation of the Effects of Alternative Diesel Fuel Formulations on Exhaust Emission Rates and Reactivity, 99-VERT2P-001-FR, College of Engineering-Center for Environmental Research and Technology, University of California-Riverside, South Coast Air Quality Management District Contract \#98102, April.

34. U.S. Environmental Protection Agency (EPA), 1989, Analysis of Economic and Environmental Effects of Methanol as an Automotive Fuel, Office of Mobile Sources, Ann Arbor, MI.

35. Kirwan, J.E., 1993, "Effects of Methanol and Fuel Sulfur Concentration on Tailpipe Emissions in a Production Variable Fuel Vehicle," SAE Transactions, Vol 102, No 4., Paper 932774, 1579-1591.

36. Auto/Oil Air Quality Improvement Research Program, 1992, Emissions and Air Quality Modeling Results from Methanol/Gasoline Blends in Prototype Flexible/Variable Fuel Vehicles, Technical Bulletin No. 7, Coordinating Research Council, Atlanta, GA.

37. Wang, M., C. Saricks, and D. Santini, 1999, Effects of Fuel Ethanol Use on Fuel-Cycle Energy and Greenhouse Gas Emissions, Center for Transportation Research, Argonne National Laboratory, ANL/ESD-38, Argonne, IL, January. 